\title{
COMUNICAÇÃo
}

[Communication]

\section{Técnica de citometria de fluxo para avaliação da produção de espécies reativas de oxigênio pelas células do líquido sinovial de eqüinos}

[Cytometry flow techniques for evaluation of reactive oxygen species produced by equine synovial cells fluid]

\author{
C.O. Massoco ${ }^{1}$, L. Carmona ${ }^{2}$, R.Y.A. Baccarin ${ }^{2 *}$ \\ ${ }^{1}$ Hospital de Eqüinos Salles Gomes, Foz e Associados - São Paulo, SP \\ ${ }^{2}$ Faculdade de Medicina Veterinária e Zootecnia - USP \\ Av. Prof. Orlando Marques de Paiva, 87 \\ 05508-000 - São Paulo, SP
}

A citometria de fluxo tem sido amplamente utilizada para se estudar as atividades fagocíticas de macrófagos e neutrófilos em humanos e animais (Bassoe et al., 1983; Johannisson et al., 1995). É considerada conveniente e mais prática que outras técnicas bioquímicas, para estudar a produção de espécies reativas de oxigênio (ERO) produzidas por células durante o processo inflamatório. A metodologia citométrica elimina a necessidade de separação prévia dos leucócitos, que, além de consumir tempo, também ativa per se a explosão oxidativa celular. A produção de ERO expressa na geração de peróxido de hidrogênio dos macrófagos e dos neutrófilos estimulados pode ser monitorada quantitativamente por citometria de fluxo usando o reagente 2'7'diacetato de diclorofluoresceína (DCFH-DA) (Hasui et al., 1989). Também foi demonstrado que a oxidação do DCFH-DA é quantitativamente proporcional à concentração de peróxido de hidrogênio gerado (Hirabayashi et al., 1985).

A degeneração da cartilagem articular em eqüinos tem sido atribuída à liberação de radicais livres os quais degradam seus componentes, tais como o colágeno, os proteoglicanos e o hialuronato (Monboisse e Braquet et al., 1984), além de prejudicar o metabolismo energético dos condrócitos (Kvam et al., 1995). O exame convencional do líquido sinovial que leva em

Recebido em 6 de dezembro de 2004

Aceito em 30 de janeiro de 2006

*Autor para correspondência (corresponding author)

E-mail:baccarin@usp.br consideração aspecto, quantidade de proteína total, viscosidade, contagem total de células nucleadas e citologia indica a presença ou não de um estado inflamatório intra-articular, mas não permite uma avaliação mais pormenorizada da atividade celular durante o processo inflamatório.

Este trabalho teve por objetivo verificar a viabilidade da técnica de citometria de fluxo em quantificar a produção de ERO proveniente das células do líquido sinovial de articulações hígidas e acometidas por artrite em eqüinos.

Utilizaram-se sete amostras de líquido sinovial de diferentes animais, colhidas de duas articulações tíbio-társicas (ArTT) e duas metacarpo-falangeanas (ArMF) hígidas, e de duas articulações tíbio-társicas (ArTT) e uma metacarpo-falangeana (ArMF) inflamadas. O líquido sinovial foi analisado segundo Hasui et al. (1985). Para a obtenção do número necessário de células para o ensaio realizaram-se centrifugação e posterior ressuspensão das amostras em solução tampão de fosfato. A magnitude da produção de ERO foi verificada pela técnica de citometria de fluxo utilizando-se um citômetro de fluxo ${ }^{1}$ em que a produção de ERO basal e induzida pela Staphylococcus aureus foi quantificada pela intensidade média de fluorescência/célula emitida pelo DCFH analisada pelo software Cell Quest Pro. As populações celulares, tais como linfócitos, neutrófilos, macrófagos e sinoviócitos não

${ }^{1}$ Becton Dickinson Immunocytometry System, San Jose, CA, USA. 
puderam ser fenotipicamente reconhecidas devido à não utilização de marcadores específicos para cada população. Contudo, baseando-se nas propriedades de tamanho e granulosidade de amostras de sangue periférico de eqüinos (Raidal et al., 1998), as quais são representadas em citogramas padrões, foi possível diferenciar populações mononucleares $(\mathrm{MN})$ das polimorfonucleares (PMN). Além disso, fez-se a análise morfológica convencional por microscopia óptica.

Na Fig. 1A, B, C e D são apresentadas quatro citogramas típicos dos leucócitos do líquido sinovial, representando o perfil de uma ArTT hígida, uma ArTT inflamada, uma ArMF hígida e uma ArMF inflamada, respectivamente. As células $\mathrm{MN}$ e as PMN correspondem, nos citogramas, às regiões ou gates R1 e R2, respectivamente. Observou-se maior densidade de PMN apenas nas articulações inflamadas, confirmado pela análise morfológica das células dos líquidos sinoviais ao microscópio óptico. A intensidade média de fluorescência emitida pelas células das respectivas amostras de líquido
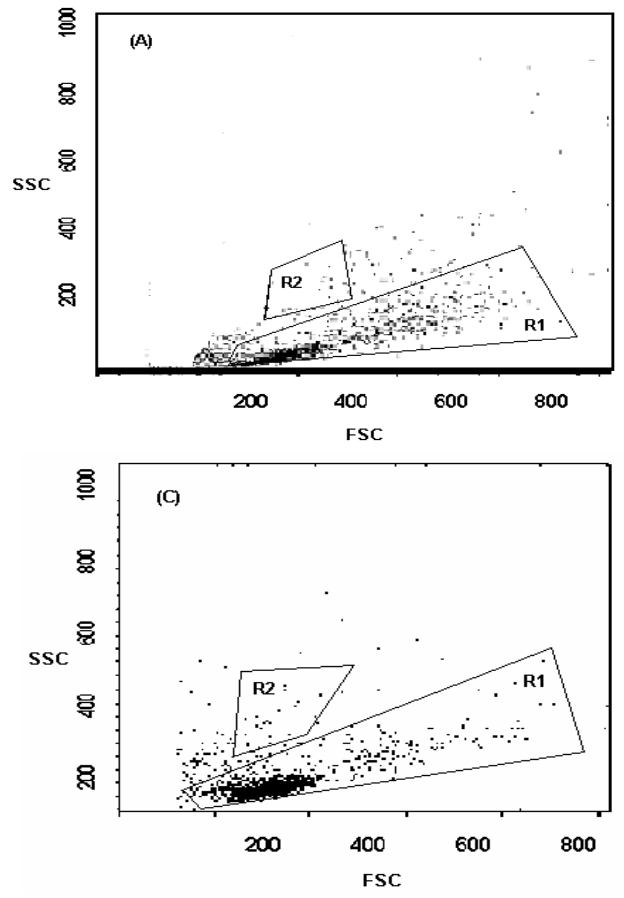

sinovial é apresentada na Tab. 1. A produção basal (sem estímulo) de ERO das células presentes nas articulações hígidas e inflamadas, tanto da ArTT como na ArMF, apresentaram valores homogêneos. No entanto, quando as células das articulações inflamadas foram incubadas com a $S$. aureus (estímulo), foi verificado um incremento no valor de fluorescência média emitida por estas células quando comparado com valores das células provenientes das articulações hígidas após a estimulação. Esse fato sugere que as vias de ativação para o desencadeamento da produção de ERO induzida por bactérias podem estar facilitadas nas células previamente ativadas pela injúria local. Estes resultados demonstraram que a técnica de citometria de fluxo foi capaz de: avaliar a produção de ERO das diferentes populações celulares do líquido sinovial de eqüinos; identificar mudanças nas características morfológicas das células presentes nas articulações inflamadas; e identificar uma diferença na densidade de células do líquido sinovial quando comparadas duas articulações.
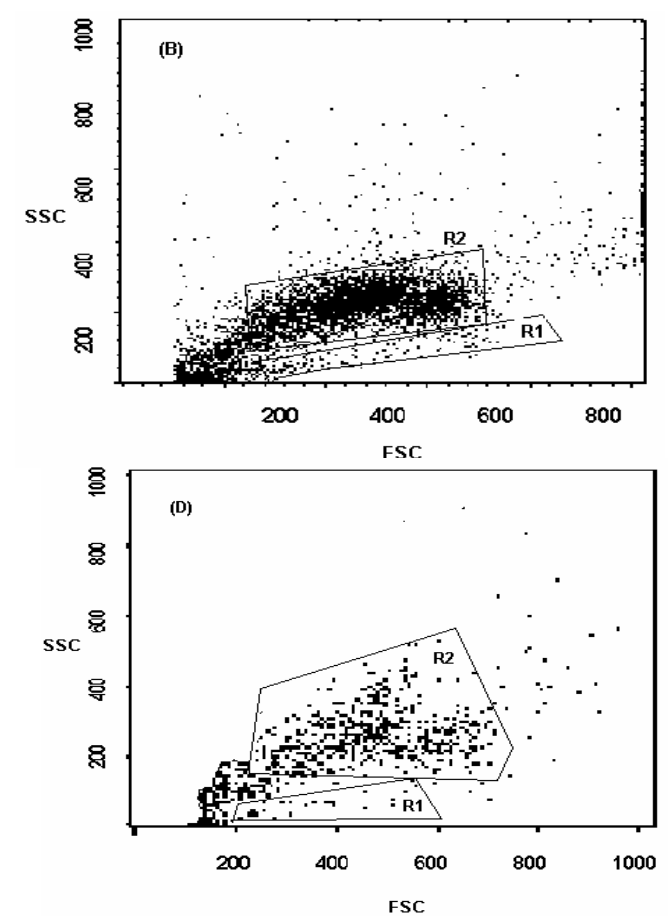

Figura 1. Citogramas representando as populações celulares presentes. A: ArTT hígida. B: ArTT inflamada. C: ArMF hígida. D: ArMF inflamada. As regiões R1 e R2 correspondem às células mononucleares $(\mathrm{MN})$ e polimorfonucleares $(\mathrm{PMN})$, respectivamente. Dentre as células $\mathrm{MN}$ estão os linfócitos, monócitos e sinoviócitos e dentre os PMN, os neutrófilos e eosinófilos. 
Tabela 1. Valores da intensidade média de fluorescência (unidades arbitrárias), emitida pelas células provenientes de articulações hígidas e inflamadas de eqüinos

\begin{tabular}{|c|c|c|c|c|c|c|c|c|}
\hline \multirow{3}{*}{ Tubo } & \multicolumn{4}{|c|}{ Articulação tíbio-társica } & \multicolumn{4}{|c|}{ Articulação metacarpofalangeana } \\
\hline & \multicolumn{2}{|c|}{ Hígida } & \multicolumn{2}{|c|}{ Inflamada } & \multicolumn{2}{|c|}{ Higida } & \multicolumn{2}{|c|}{ Inflamada } \\
\hline & $\mathrm{MN}$ & PMN & $\mathrm{MN}$ & PMN & $\mathrm{MN}$ & PMN & $\mathrm{MN}$ & PMN \\
\hline$\overline{\text { PBS }}$ & 2,2 & 3,2 & 2,7 & 1,3 & 2,8 & 2,9 & 2,1 & 3,1 \\
\hline DCFH & 34,0 & 26,1 & 37,0 & 30,1 & 54,2 & 23,4 & 35,6 & 33,2 \\
\hline S.aureus & 145,2 & 55,0 & 370,4 & 152,3 & 121,0 & 47,8 & 330,2 & 143,2 \\
\hline
\end{tabular}

$\mathrm{MN}=$ células mononucleares; $\mathrm{PMN}=$ células polimorfonucleares; $\mathrm{PBS}=$ solução de tampão fosfato; $\mathrm{DCFH}=2$ '7'diclorofluoresceína.

Palavras-chave: eqüino, citometria de fluxo, líquido sinovial, explosão oxidativa

\section{ABSTRACT}

Using the cytometry flow analysis and adapting the method proposed by Hasui et al. (1985), it was possible to quantify the reactive oxygen species (ROE) produced by distinct cell populations of the synovial fluid from rigid and inflamed joints in horses, and to identify an increase in the polymorphonuclear cells population densities in the inflamed joints. These data strengthen the premise that cytometry flow techniques can contribute for future researches on the articular cartilage degeneration in horses.

Keywords: horse, flow cytometric, synovial fluid, oxidative burst.

\section{REFERÊNCIAS BIBLIOGRÁFICAS}

BASSOE, C.F.; LAERUM, O. D.; SOLBERG, C. O. et.al Phagocytosis of bacteria by human leucocytes measured by flow cytometry. Proc. Soc. Exper. Biol. Med., v.174, p.182-186, 1983a.

HASUI, M.; HIRABAYASHI, Y.; KOBAYASHI, Y. Simultaneous measurement by flow cytometry of phagocytosis and hydrogen peroxide production of neutrophils in whole blood. J. Immunol. Meth., v.117, p.53-58, 1989.

HIRABAYASHI, Y.; TANIUCHI, S.; KOBAYASHI, Y. A quantitative assay of oxidative metabolism by neutrophils in whole blood using flow cytometry. J. Immunol. Meth., v. 82 , p. $253-259,1985$.

JOHANNISSON, A.; GRO-NDAHL， G.; DEMMERS, S. et al M. Flow-cytometric studies on the phagocytic capacities of equine neutrophils. Acta Vet. Scand., v. 36, p. 553-562, 1995.

KVAM, B.J.; FRAGONAS, E.; DEGRASSI, A. et al. Oxygen derived free radical (ODFR) action on hyaloronan (HA) on two HA ester derivatives and on the metabolism of articular chondrocytes. Expt. Cell. Res., v.218, p.79, 1995.

MONBOISSE, J.; BRAQUET, P. Oxygen-free radicals as mediators of collagen breakage. Agents Actions, v. 15, p.49-50, 1984.

RAIDAL, S.L.; BAILEY, G.D.; LOVE, D.N. Flow cytometric determination of oxidative burst activity of equine peripheral blood and bronchoalveolar lavage derived leukocytes. Vet. J., v.156, p.117-126, 1998. 